(2) Open Access Full Text Article

\title{
Hyperosmolar nonketotic hyperglycemic coma induced by methylprednisolone pulse therapy for acute rejection after liver transplantation: a case report and review of the literature
}

\author{
This article was published in the following Dove Press journal: \\ Transplant Research and Risk Management \\ 22 December 2014 \\ Number of times this article has been viewed
}

\author{
Jian Zhou* \\ Weiqiang Ju* \\ Xiaopeng Yuan \\ Xiaofeng Zhu \\ Dongping Wang \\ Xiaoshun $\mathrm{He}$ \\ Organ Transplant Center, First \\ Affiliated Hospital, Sun Yat-sen \\ University, Guangzhou, People's \\ Republic of China \\ *These authors contributed equally \\ to this work
}

\begin{abstract}
Hyperosmolar nonketotic hyperglycemic coma (HNKHC) is a serious, rare complication induced by methylprednisolone (MP) pulse therapy for acute rejection after orthotopic liver transplantation (OLT). Herein, we report an unusual case of a 58-year-old woman who experienced acute rejection at 30 months after OLT, only one case in which HNKHC resulted in MP pulse therapy for acute rejection in all 913 recipients in our center. The general morbidity of HNKHC was $1.09 \%$ in this study. HNKHC is characterized by rapid onset, rapid progression, and a lack of specific clinical manifestations. High-dose MP management was a clear risk factor. The principle of treatment included rapid rehydration, low-dose insulin infusion, and correcting disorders of electrolytes and acidosis. In conclusion, clinicians considering MP pulse therapy after OLT should be alert to the occurrence of HNKHC.
\end{abstract}

Keywords: liver transplantation, complications, hyperosmolar nonketotic hyperglycemic coma, methylprednisolone pulse therapy, principle of treatment

\section{Introduction}

Hyperosmolar nonketotic hyperglycemic coma (HNKHC) is a rare, serious acute complication of diabetes mellitus. It is characterized by a syndrome of serious hyperglycemia, hypernatremia, dehydration, high plasmatic osmotic pressure, and no obvious ketoacidosis, as well as different levels of consciousness disorder or coma. ${ }^{1,2}$ Notably, two-thirds of internal medicine patients with HNKHC have no history of diabetes mellitus or only mild symptoms of diabetes before the onset of HNKHC. Published data have shown that the mortality rate of this disease is as high as $50 \%-60 \%$. Currently, the mortality of HNKHC is declining, owing to increasing improvement of clinician awareness and diagnostic level and treatment, but it is still as high as $11 \%-16 \%{ }^{2,3}$ However, HNKHC after orthotopic liver transplantation (OLT) has yet to be reported in the literature. This study sought to present our experience regarding HNKHC induced by methylprednisolone (MP) pulse therapy (short-term, high-dose methylprednisolone) for acute rejection after OLT.

\section{Case report}

The recipient was a 58-year-old woman who had had OLT performed 30 months earlier, owing to hepatitis B cirrhosis and primary biliary cirrhosis, and had no history of diabetes in the pre- and postoperative period. The donor was derived from donation after cardiac death in a male, 32 years old, due to an accident. The recipient was admitted to 
hospital owing to liver-function abnormalities. Maintenance immunosuppressive treatment prior to admission included tacrolimus ( $2 \mathrm{mg} /$ day) and sirolimus (1 mg/day). After admission, liver-function tests were abnormal (Table 1). Computed tomography examination of the upper abdomen showed that graft size and shape were normal, but multiple intrahepatic bile ducts presented branch calcification, the causes of which were associated with autoimmune and diffuse dilatation of the intrahepatic bile duct. A biopsy of the liver showed the possibility of acute rejection (Figure 1).

MP pulse therapy was tapered, with daily doses of $1,000 \mathrm{mg}, 500 \mathrm{mg}, 240 \mathrm{mg}, 200 \mathrm{mg}, 160 \mathrm{mg}, 120 \mathrm{mg}$, and $80 \mathrm{mg}$ on the first round over a total of 7 days. At the end of the first MP therapy, owing to the poor recovery of liver function (Table 1), the second round of MP pulse therapy, like the first, was managed for only 2 days. The patient suddenly presented clinical manifestations of confusion of the consciousness, rapidly appearing coma, weakness and quickening of the pulse, reduction of pulse pressure, decrease in blood pressure, reduction of urine volume, dry skin, sagging, and enophthalmos. Her laboratory test results are shown in Table 2 . We diagnosed the patient with HNKHC. After diagnosis with HNKHC, emergency treatment should be started immediately. Detailed measures consisted of rapid rehydration, low-dose insulin infusion, and correcting disorders of electrolytes and acidosis. After 24 hours' comprehensive treatment, the patient's blood sugar had dropped to normal, and urine sugar, osmotic pressure, electrolytes, and arterial blood gas were normal (Table 2). Her consciousness became clear. The patient ultimately recovered and was discharged, and after 6 months of followup had not experienced HNKHC again.

\section{Discussion}

The morbidity of HNKHC is low, only $0.04 \%$ in the general population, ${ }^{4}$ but significantly increases to $1.09 \%$ after OLT in our center. Owing to no specific clinical manifestations of HNKHC, it is absolutely necessary to analyze the patients' condition and laboratory findings before diagnosis, in order to reduce the chances of misdiagnosis and mistreatment. In

Table I Liver function in different periods

\begin{tabular}{lllll}
\hline $\begin{array}{l}\text { Liver } \\
\text { function }\end{array}$ & $\begin{array}{l}\text { On } \\
\text { admission }\end{array}$ & $\begin{array}{l}\text { End of first } \\
\text { MP therapy }\end{array}$ & $\begin{array}{l}\text { Out of } \\
\text { hospital }\end{array}$ & $\begin{array}{l}\text { Reference } \\
\text { value }\end{array}$ \\
\hline AST (U/L) & 163 & 153 & 40 & $\mathrm{I}-37$ \\
ALT (U/L) & 114 & 266 & 55 & $\mathrm{I}-40$ \\
TBIL (mmol/L) & 105.9 & 142 & 28.8 & $3-22$ \\
\hline
\end{tabular}

Abbreviations: MP, methylprednisolone; ALT, alanine aminotransferase; AST, aspartate aminotransferase; TBIL, total bilirubin.

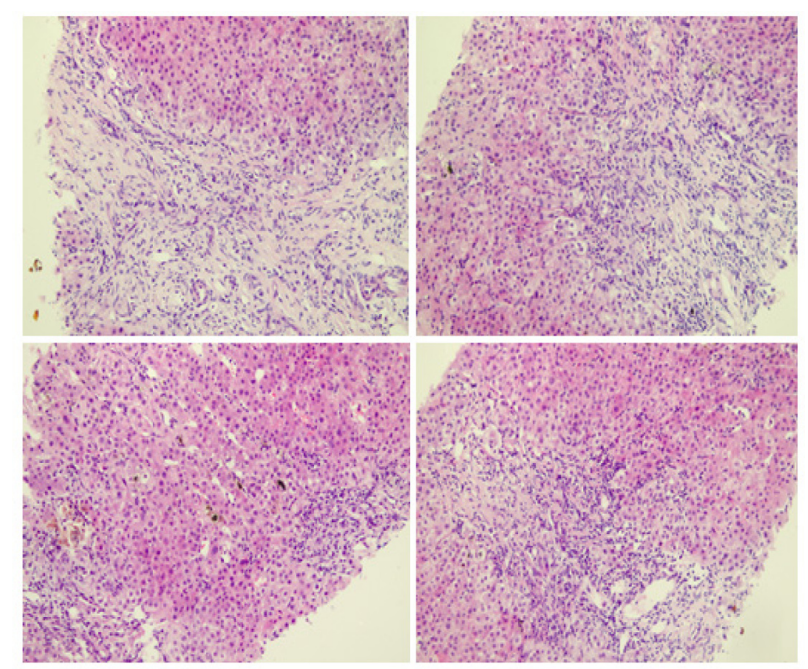

Figure I Histologic findings of acute rejection after liver transplantation. The histologic characteristics indicated acute injection, including normal structure of hepatic lobules, fibrous proliferation of interlobular portal area, small bile-duct hyperplasia, visible lymphocyte infiltration around the small bile-duct wall, liver cell mild edema with cholestasis, and point necrosis.

addition, great changes taken place before and after OLT on the body. Therefore, it is very important for clinical transplant surgeons to learn and master common predisposing causes of HNKHC in order to make an early diagnosis. These common risk factors include 1) stress state, 2) insufficient water intake, 3) too much water loss, 4) high sugar intake, and 5) drugs, such as immunosuppressants (these can cause or aggravate insulin resistance, elevate blood sugar, increase dehydration, or even directly inhibit insulin secretion and reduce its sensitivity, thus inducing the disease), and 6) others, such as diabetic nephropathy, acute or chronic renal failure. Research has shown that the use of glucocorticoids can

Table 2 Laboratory tests of HNKHC pre- and posttreatment

\begin{tabular}{|c|c|c|c|}
\hline Laboratory tests & $\begin{array}{l}\text { Prior } \\
\text { treatment }\end{array}$ & Posttreatment & $\begin{array}{l}\text { Reference } \\
\text { value }\end{array}$ \\
\hline $\begin{array}{l}\text { Serum glucose } \\
(\mathrm{mmol} / \mathrm{L})\end{array}$ & 33 & 7 & $2.9-6.0$ \\
\hline Potassium (mmol/L) & 4.43 & 4.6 & $3.5-5.3$ \\
\hline Sodium (mmol/L) & 146 & 140 & $135-145$ \\
\hline Chloride (mmol/L) & 115 & 100 & $96-110$ \\
\hline Creatinine $(\mu \mathrm{mol} / \mathrm{L})$ & 109 & 105 & $53-115$ \\
\hline $\begin{array}{l}\text { Urea nitrogen } \\
(\mathrm{mmol} / \mathrm{L})\end{array}$ & 14.5 & 8.5 & $2.9-8.6$ \\
\hline $\begin{array}{l}\text { Osmotic pressure } \\
(\mathrm{mOsm} / \mathrm{L})\end{array}$ & 339 & 290 & $275-295$ \\
\hline Urine sugar & Positive $(+1++)$ & Negative & \\
\hline Urine acetone bodies & Negative & Negative & \\
\hline \multicolumn{4}{|l|}{ Arterial blood gas } \\
\hline $\mathrm{pH}$ & 7.35 & 7.4 & $7.35-7.45$ \\
\hline $\mathrm{HCO}_{3}(\mathrm{mmol} / \mathrm{L})$ & 21 & 23 & $22-27$ \\
\hline
\end{tabular}

Abbreviation: HNKHC, hyperosmolar nonketotic hyperglycemic coma. 
decrease peripheral glucose, increase hepatic glucose output, and at the same time reduce the secretion of insulin. ${ }^{5}$ Also, the effects of glucocorticoids on blood glucose are related to their cumulative dose. ${ }^{6}$ Apart for glucocorticoids, tacrolimus also can induce insulin resistance. ${ }^{7}$ Generally speaking, several kinds of immunosuppressants, such as tacrolimus, mycophenolate mofetil, and prednisolone, are needed. Therefore liver-transplant recipients belonged to a high-risk group of HNKHC patients.

The diagnosis of HNKHC depends on the clinical manifestation and laboratory examination. Typical clinical manifestations can be divided into 1) the prodromal stage, referring to the period before the onset of neurological symptoms and coma, 2) the typical period, mainly including severe dehydration and nervous system symptoms, and 3) the symptoms and signs of concomitant diseases. With regard to laboratory test findings for $\mathrm{HNKHC}$, several studies have put forward the following criteria: 1) blood glucose $\geq 33 \mathrm{mmol} / \mathrm{L}, 2$ ) effective osmotic pressure $\geq 320 \mathrm{mmol} / \mathrm{L}$, and 3 ) arterial blood gas examination showing $\mathrm{pH} \geq 7.30$ or $\mathrm{HCO}_{3}{ }^{-} \geq 15 \mathrm{mmol} / \mathrm{L}$ in serum. Notably, HNKHC could concurrently accompany the possibility of diabetic ketoacidosis (DKA) ${ }^{8,9}$ or lactic acidosis. In addition, the hyperosmolar state seen in some cases is due to hypernatremia and low blood sugar, so urine-ketone positivity, acidosis, and blood glucose below $33 \mathrm{mmol} / \mathrm{L}$ cannot be used as evidence for the diagnosis of negative HNKHC. There is an obvious hyperosmotic state in HNKHC patients without exception, and if coma patients presented effective plasma osmolality of less than $320 \mathrm{mOsm} / \mathrm{L}$, then other causes resulting in coma should be considered.

The pathogenesis of HNKHC is complex, and has not yet been fully clarified. Its occurrence is based on glucosemetabolism disorders to different degrees. Under a variety of incentives, the action of glucose metabolism disorder is further aggravated, pancreatic islets responsive to glucose stimulation decreased, insulin secretion decreased, and decomposition of liver glycogen increased to a higher lever of blood sugar. Significant hyperglycemia and glycosuria cause osmotic diuresis, resulting in high loss of both water and electrolyte loss from the kidney. Hyperglycemia, dehydration, and plasma hyperosmosis eventually lead to the occurrence of HNKHC.

The diagnoses of HNKHC and DKA are clinically very easy to confuse, ${ }^{10-14}$ because both of them are acute diabetic complications caused by a lack of insulin secretion. The difference is that HNKHC is common in the elderly, and dehydration, hyperosmosis, and hyperglycemia is more serious, but without or with only mild ketoacidosis.
While DKA is more common in young people with type 1 diabetes, the syndrome of hyperglycemia and dehydration in those patients were less severe, but ketoacidosis was more serious. ${ }^{13,15-17}$ Notably, HNKHC and DKA are two extremes of one continuous disease spectrum, rather than two different diseases. Therefore, hyperglycemia and a hyperosmotic state are sometimes seen in DKA patients, and significant ketoacidosis cannot be completely ruled out of HNKHC diagnosis.

In conclusion, the prognosis of HNKHC depends on rapid rehydration, low-dose insulin infusion, and correcting disorders of electrolytes and acidosis. Even though the recipients have no history of diabetes before and after OLT, HNKHC should be constantly watched for in prednisolone pulse therapy recipients.

\section{Acknowledgment}

This work was supported by grants from the Key Clinical Project from the Ministry of Health (159) and the PhD Programs Foundation of the Ministry of Education of the People's Republic of China (20130171120076).

\section{Disclosure}

The authors report no conflicts of interest in this work.

\section{References}

1. Kitabchi AE, Umpierrez GE, Murphy MB, Kreisberg RA. Hyperglycemic crises in adult patients with diabetes: a consensus statement from the American Diabetes Association. Diabetes Care. 2006;29: 2739-2748.

2. Kitabchi AE, Umpierrez GE, Fisher JN, Murphy MB, Stentz FB. Thirty years of personal experience in hyperglycemic crises: diabetic ketoacidosis and hyperglycemic hyperosmolar state. J Clin Endocrinol Metab. 2008;93:1541-1552.

3. Fadini GP, de Kreutzenberg SV, Rigato M, et al. Characteristics and outcomes of the hyperglycemic hyperosmolar non-ketotic syndrome in a cohort of 51 consecutive cases at a single center. Diabetes Res Clin Pract. 2011;94:172-179.

4. Abbott KC, Bernet VJ, Agodoa LY, Yuan CM. Diabetic ketoacidosis and hyperglycemic hyperosmolar syndrome after renal transplantation in the United States. BMC Endocr Disord. 2003;3:1-14.

5. Penfornis A, Kury-Paulin S. Immunosuppressive drug-induced diabetes. Diabetes Metab. 2006;32:539-546.

6. Pham PT, Pham PC. Assessing the risk of post-transplantation diabetes mellitus with an oral glucose tolerance test. Nat Clin Pract Nephrol. 2008;4:600-601.

7. Van Hooff JP, Christiaans MH, van Duijnhoven EM. Evaluating mechanisms of post-transplant diabetes mellitus. Nephrol Dial Transplant 2004;19 Suppl 6:vi8-vil2.

8. Trachtenbarg DE. Diabetic ketoacidosis. Am Fam Physician. 2005;71: 1705-1714.

9. Ali Z, Levine B, Ripple M, Fowler DR. Diabetic ketoacidosis: a silent death. Am J Forensic Med Pathol. 2012;33:189-193.

10. Ellemann K, Soerensen JN, Pedersen L, Edsberg B, Andersen OO. Epidemiology and treatment of diabetic ketoacidosis in a community population. Diabetes Care. 1984;7:528-532. 
11. Pinhas-Hamiel O, Dolan LM, Zeitler PS. Diabetic ketoacidosis among obese African-American adolescents with NIDDM. Diabetes Care. 1997;20:484-486.

12. Valabhji J, Watson M, Cox J, Poulter C, Elwig C, Elkeles RS. Type 2 diabetes presenting as diabetic ketoacidosis in adolescence. Diabet Med. 2003;20:416-417.

13. Kitabchi AE, Wall BM. Diabetic ketoacidosis. Med Clin North Am. 1995;79:9-37.

14. Kitabchi AE, Umpierrez GE, Murphy MB, et al. Hyperglycemic crises in diabetes. Diabetes Care. 2004;27 Suppl 1:S94-S102.
15. Kitabchi AE, Umpierrez GE, Miles JM, Fisher JN. Hyperglycemic crises in adult patients with diabetes. Diabetes Care. 2009;32:1335-1343.

16. Guh JY, Lai YH, Yu LK, Shin SJ, Tsai JH. Evaluation of ventilatory responses in severe acidemia in diabetic ketoacidosis. Am J Nephrol. 1997; 17:36-41.

17. Burge MR, Garcia N, Qualls CR, Schade DS. Differential effects of fasting and dehydration in the pathogenesis of diabetic ketoacidosis. Metabolism. 2001;50:171-177.

\section{Publish your work in this journal}

Transplant Research and Risk Management is an international, peerreviewed open access journal focusing on all aspects of transplantation and risk management to achieve optimal outcomes in the recipient improving survival and quality of life. The journal welcomes submitted papers covering original research, basic science, clinical studies, reviews \& evaluations, guidelines, expert opinion and commentary, case reports and extended reports. The manuscript management system is completely online and includes a very quick and fair peer-review system, which is all easy to use. Visit http://www.dovepress.com/ testimonials.php to read real quotes from published authors. 